\title{
SISTEM TRANSFER PULSA TELEPON SELULER BERBASIS SHORT MESSAGE SERVICE (SMS) Studi Kasus: P. T. Indosat Multimedia Mobile (IM3)
}

\author{
Ahmad Nugraha R. ${ }^{1}$, Fazmah Arif Yulianto $^{2}$, Suyanto $^{3}$ \\ Jurusan Teknik Informatika Sekolah Tinggi Teknologi Telkom, Bandung \\ sif99120@stttelkom.ac.id ${ }^{1}, \underline{\text { fay @stttelkom.ac.id }}^{2}, \underline{\text { suy @ stttelkom.ac.id }}^{3}$
}

\begin{abstract}
Abstrak
Salah satu kendala dalam berkomunikasi seluler, terutama bagi pengguna layanan prabayar, adalah keterbatasan pulsa. Salah satu alternatif untuk mengatasi kendala tersebut adalah mekanisme Sistem Transfer Pulsa Telepon Seluler Berbasis SMS. Pelanggan dengan nilai pulsa lebih banyak dapat memindahkan sebagian nilai pulsanya kepada pelanggan lain yang memiliki pulsa terbatas atau bahkan habis. Transfer pulsa dilakukan dengan mengirimkan pesan SMS yang berisi permintaan transfer sejumlah nilai pulsa ke nomor lain pada operator yang sama. Berdasarkan pengujian kuantitatif, diperlukan durasi 3,504 detik untuk proses di server dengan sampel data 50.000 record. Pengukuran menunjukkan sistem mampu menyelesaikan satu transaksi SMS rata-rata selama 8,759 detik. Lamanya proses ini masih memenuhi QoS transaksi SMS yang mensyaratkan satu transaksi SMS harus selesai sebelum 10 detik. Tingginya ekspektasi responden, penilaian terhadap sistem, dan kemudahan format pesan menunjukkan sistem ini dapat dikatakan berhasil dan cukup menjanjikan untuk implementasi.
\end{abstract}

Kata Kunci: transfer pulsa, SMS

\section{Abstract}

Users of pre-paid cellular telephone service often face a problem with their pulse credit. Limited pulse credit may lead to a broken communication. The mechanism we propose in this paper, SMS-Based Cellular Phone Pulse Credit Transfer, is the one which allow someone to transfer some of his/her pulse credit to someone else if both of the subscriber is in the same cellular operator. To transfer some credit, someone only has to specify the amount of transfer and the destination number. The test result shows that with 50,000 records in the database, a typical server is able to handle each request in only 3.504 seconds. From the user point of view, each SMS transaction only take 8.759 seconds. It is below the 10 seconds required QoS threshold for SMS transaction. Our survey says that this system can fulfill customer expectation to (temporarily) handle the limited pulse credit problem and is promising enough to be implemented in the real system.

Keywords: pulse credit transfer, SMS

\section{Pendahuluan}

Telekomunikasi telah menjadi hal yang amat penting bagi perkembangan peradaban manusia. Perkembangan layanan-layanan telekomunikasi semakin pesat dari hari ke hari. Tak mengherankan jika di masa sekarang, telekomunikasi menjadi kebutuhan yang amat vital bagi manusia modern dengan keragaman aktivitas dan mobilitasnya.

Salah satu kendala dalam penggunaan teknologi telekomunikasi, baik telepon tetap maupun bergerak, adalah masalah biaya. Pulsa sebagai satuan biaya telekomunikasi merupakan sesuatu yang terbatas bagi pengguna. Bagi pengguna telepon seluler, khususnya yang menggunakan layanan prabayar, keterbatasan pulsa amatlah merugikan bagi kelancaran proses komunikasi.

Mekanisme isi ulang pulsa, baik melalui pembelian voucher maupun isi ulang melalui bank, tidak selamanya dapat secara reguler dilakukan. Pemilik telepon seluler yang tidak memiliki persediaan keuangan memadai atau yang tidak memiliki rekening di bank akan mengalami kesulitan berkomunikasi ketika cadangan pulsanya habis. Padahal, ketika cadangan pulsa habis, komunikasi bisa saja sedang menjadi kebutuhan yang saat penting, baik untuk pengiriman SMS maupun sekedar melakukan missed call.

Suatu solusi alternatif yang ditawarkan untuk mengatasi masalah tersebut adalah Sistem Transfer Pulsa melalui layanan SMS. Sistem ini memungkinkan pengiriman sejumlah nilai pulsa dari satu nomor ke nomor lain, pada sistem prabayar dalam satu operator. Seseorang yang memiliki pulsa cukup banyak (melebihi suatu batas tertentu) dapat mengirimkan pulsanya ke penerima yang sedang tidak memiliki pulsa atau nilai pulsanya sangat kecil. Setelah penerima mendapatkan kiriman pulsa, maka ia dapat langsung melakukan proses komunikasi kembali. Sampai saat sistem ini dikembangkan, belum ada satupun operator selular di Indonesia yang menerapkan sistem transfer pulsa.

Adapun penggunaan teknologi SMS sebagai media pengiriman pulsa ini adalah karena kemudahan penggunaannya, murah, fleksibel, dan telah menjadi layanan sangat sangat populer saat ini. 
SMS selain banyak bermanfaat bagi pengguna, juga menjadi sumber pendapatan yang potensial bagi operator. Sistem ini diharapkan dapat memberikan kontribusi bagi kelangsungan proses komunikasi pelanggan, dan menjadi sebuah diferensiasi produk yang juga dapat memberikan kontribusi bagi operator untuk meningkatkan pendapatan dan meraih lebih banyak pelanggan.

Pembuatan dan analisis aplikasi SMS ini dilakukan hanya pada sistem pra-bayar PT. Indosat M3 (IM3 Smart). Hal ini dilakukan mengingat transfer pulsa melibatkan akses ke basis data billing pelanggan, sehingga akan terlalu rumit (berkaitan dengan masalah birokrasi) jika harus dilakukan juga proses update basis data billing lintas operator.

Untuk mendapatkan data kinerja, dilakukan pengukuran secara kuantitatif dan kualitatif. Pengukuran kuantitatif meliputi response time dan throughput (trafik) yang dapat dilayani oleh sistem. Pengujian kualitatif melibatkan responden untuk melihat tingkat kepuasan calon pengguna layanan.

\section{Layanan SMS dan Tagihan Pra-bayar GSM}

\subsection{Jaringan GSM}

Global System for Mobile Communication atau biasa disebut GSM adalah suatu teknologi seluler digital yang dikembangkan pertama kali oleh Group Special Mobile di Eropa pada tahun 1982. Pada awalnya, teknologi ini dirancang untuk bekerja pada frekuensi 900 MHz (GSM 900). Pada perkembangan selanjutnya, teknologi GSM mulai dioperasikan pada frekuensi $1800 \mathrm{MHz}$ atau yang biasa juga disebut DCS 1800[4].

Secara garis besar ada tiga komponen pembangun jaringan GSM, yaitu :

a. Mobile Station (MS)

Merupakan perangkat fisik yang secara langsung digunakan oleh pelanggan GSM untuk mengakses layanan sistem komunikasi bergerak yang ditawarkan. Pada MS terdapat SIM Card (Subscriber Identity Module) yang berisi nomor identitas pelanggan atau MSISDN (Mobile Subscriber Integrated Service Digital Network).

b. Base Station System (BSS)

BSS terdiri dari :

- Base Station Controller (BSC)

- Base Transceiver Station (BTS)

c. Network Switching and Sub-System (NSS)

NSS berfungsi sebagai penghubung atau interface pada jaringan GSM dengan jaringan telekomunikasi lainnya. Komponen NSS pada jaringan GSM terdiri dari:

- Mobile Services Switching Center (MSC)

- Home Location Register (HLR)

- Autentication Center (AuC)

- Visitor Location Register (VLR)

- Equipment Identity Register (EIR)

\subsection{Short Message Service (SMS)}

Short Message Service (SMS) adalah fasilitas pada teknologi GSM yang memungkinkan pengiriman dan penerimaan pesan singkat sebanyak maksimal 160 karakter dari MS [5]. Pada Gambar 2 dijelaskan infrastruktur SMS pada jaringan GSM.

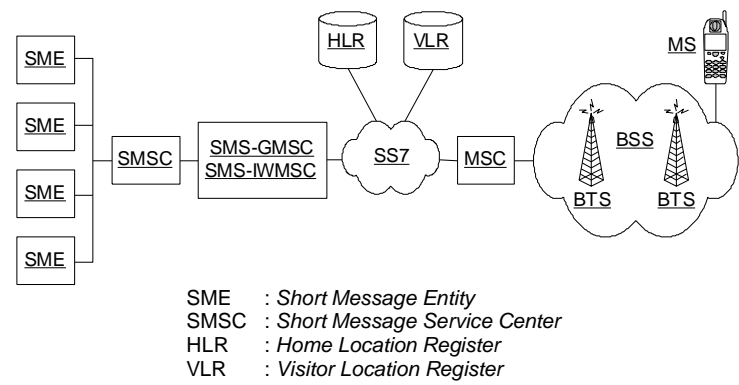

Gambar 1. Infrastruktur SMS

Berdasarkan fungsinya dalam pengiriman SMS, fungsi MSC (Mobile Services Switching Center) dapat dibedakan menjadi dua :

- SMS-GMSC (Gateway MSC for Short Message Service), yaitu fungsi dari MSC yang mampu menerima pesan dari SC, kemudian mencari informasi routing ke HLR, selanjutnya mengirim ke VMSC di mana pelanggan berada.

- SMS-IWMMSC (Internetworking MSC for Short Message Service), yaitu fungsi dari MSC yang mampu mengirim pesan dari PLMN (Public Land Mobile Network) kemudian meneruskannya ke SC.

Short Message Point to Point Services menyediakan dua layanan dasar, yaitu :

- SM MT (Short Message Mobile Terminated Point to Point) adalah kemampuan sistem GSM untuk mentransfer pesan singkat dari SC ke suatu MS, serta mengirimkan informasi pengiriman, baik berupa laporan keberhasilan ataupun laporan kegagalan pengiriman.

- SM MO (Short Message Mobile Originating Point to Point) adalah kemampuan sistem GSM untuk mentransfer pesan singkat dari suatu MS ke SME (Short Message Entity) melalui SC, serta memberikan informasi status pengiriman.

\subsection{Sistem Layanan Pra-bayar}

\subsubsection{Sistem Billing}

Sistem billing adalah sistem yang mengolah informasi tagihan biaya komunikasi (pemakaian pulsa) oleh pelanggan. Sistem tersebut mengolah data pemakaian pulsa pelanggan menjadi biaya yang dikenakan sesuai jumlah pemakaian pulsa. Pada pelanggan prabayar, besarnya nilai pulsa yang dimiliki oleh pelanggan telah terdaftar pada sistem, sehingga ketika pelanggan melakukan pemakaian 
pulsa, maka biaya yang dikenakan kemudian akan dikurangkan pada nilai awal pulsa sebelum komunikasi terjadi. Dengan sistem billing yang real time ini, data pemakaian pulsa yang dihasilkan oleh sistem dapat dibaca secara langsung sesaat setelah pelanggan melakukan pemakaian pulsa[5].

Saat ini dikenal dua buah sistem berlangganan pada jaringan telepon seluler, yaitu sistem prabayar (prepaid) dan sistem pascabayar (postpaid). Sistem prabayar mengharuskan pelanggan memiliki sumber daya (pulsa) terlebih dahulu untuk mendapatkan jasa atau fasilitas telekomunikasi. Sementara pada sistem pascabayar, pelanggan menggunakan dahulu jasa/fasilitas, yang kemudian pada periode tertentu pelanggan dikenakan tagihan.

\subsubsection{Konsep Layanan Prabayar}

Layanan prabayar merupakan salah satu produk aplikasi Intelligent Network (IN) untuk jaringan GSM. Layanan prabayar digunakan karena memiliki keunggulan dari sisi kepraktisan penggunaan dan kecepatannya. Seorang pelanggan prabayar tidak memerlukan prosedur yang rumit untuk berlangganan. Pada jaringan GSM, untuk menjadi pelanggan layanan prabayar dapat langsung membeli paket nomor perdana untuk mendapatkan nomor identitas pelanggan atau MSISDN (Mobile Subscriber Integrated Service Digital Number) tanpa harus menyertakan identitas pribadi dan proses registrasi yang membutuhkan waktu relatif lebih lama. Pelanggan hanya tinggal memasang kartu SIM (Subscriber Identity Module) pada ponsel untuk kemudian dapat langsung mengaktifkannya. Pemakaian pulsa pelanggan prabayar dapat diakses setiap waktu dan dimonitor terus oleh operator[6].

\subsubsection{Arsitektur Jaringan Prabayar}

Arsitektur jaringan prabayar terdiri atas komponen-komponen GSM dan IN serta perangkat tambahan pendukung. Arsitektur sistem prabayar di PT. Indosat M3 diilustrasikan pada Gambar 2 .

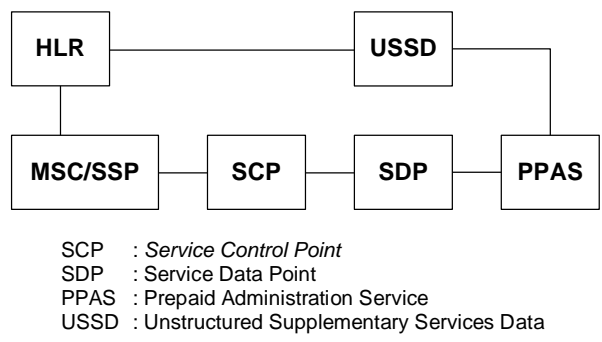

Gambar 2. Arsitektur Sistem Pra-bayar IM3

\subsubsection{Rating Gateway (RG)}

Rating Gateway (RG) adalah sebuah sistem pada jaringan IM3 yang menjadi interface antara aplikasi dengan basis data billing[3]. Aplikasiaplikasi yang bersifat Value Added Service (VAS) tidak hanya dioperasikan oleh operator, tetapi juga oleh Content Provider atau Third Party, yang tentunya tidak diperkenankan untuk memiliki akses langsung dengan basis data billing. Dengan adanya Rating Gateway, keamanan dan kerahasiaan data billing dan data pelanggan menjadi lebih terjaga.

Rating Gateway bertujuan untuk memberi jalan agar content provider bisa mengakses dan mengubah data pulsa pelanggan sesuai permintaan pelanggan. Rating Gateway terdiri dari dua bagian yaitu Content Provider Agent Server (CPAS) dan Content Provider Agent Client (CPAC).

Saat ini RG dapat diakses melalui CPAC yang menggunakan script untuk Linux, Sun Solaris, Delphi, Visual Basic, PHP, dan ASP, dalam bentuk sebuah API (Application Program Interface).

\section{Pengembangan Sistem Aplikasi Transfer Pulsa via SMS}

Berikut ini akan dijelaskan gambaran umum mengenai infrastruktur jaringan untuk implementasi sistem transfer pulsa.

\subsection{Infrastruktur Jaringan}

Pada Gambar 3 diperlihatkan lingkungan implementasi sistem transfer pulsa. Aplikasi transfer pulsa ditempatkan pada Application Server. Modul ini berinteraksi dengan SMSC menggunakan protokol SMPP untuk menerima SMS yang berisi permintaan transfer (request) dan mengirimkan SMS konfirmasi. Transfer pulsa yang berupa pemindahan sejumlah kredit dari satu account ke account lain, melibatkan operasi terhadap basis data pengguna layanan operator. Dengan alasan keamanan, aplikasi tidak langsung berinteraksi dengan server basis data. Semua operasi pengubahan data dilewatkan ke Rating Gateway menggunakan protokol TCP/IP. Rating Gateway kemudian berinteraksi dengan server basis data untuk mengeksekusi operasi tersebut.

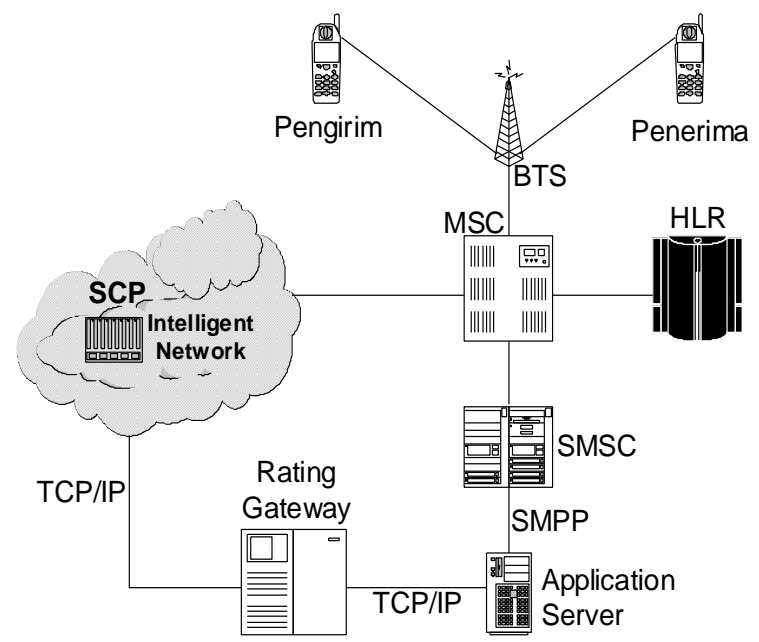

Gambar 3. Lingkungan Implementasi Sistem 


\subsection{Mekanisme Kerja}

Mekanisme kerja dari sistem transfer pulsa via SMS ini adalah sebagai berikut :

- Pelanggan harus terlebih dahulu melakukan pendaftaran di Sistem Transfer Pulsa untuk dapat menggunakan fasilitas transfer pulsa. Pada proses ini, pelanggan memasukkan login dan password khusus yang nantinya akan digunakan untuk autentikasi.

- Request pesan dikirim ke nomor tujuan tertentu (untuk pengujian digunakan nomor 5555)

- Pelanggan yang memiliki jumlah pulsa berlebih dapat mengirimkan sejumlah nilai pulsa ke pelanggan lain yang memiliki jumlah pulsa kecil atau habis, agar penerima pulsa dapat tetap berkomunikasi (baik via SMS, missed call, atau melakukan panggilan). Untuk pengujian, ditetapkan batas minimal pulsa yang dimiliki untuk dapat melakukan transfer adalah sebesar Rp 10.000,- + jumlah pulsa yang akan dikirim + biaya kirim. Setiap kali transfer, pengirim akan dikenakan tagihan sebesar Rp 1000,-

- Sistem menyediakan fasilitas ganti password dan hapus account.

- Pulsa hasil pengiriman tidak memperpanjang masa berlaku kartu.

\subsection{Rancangan Sistem}

Masukan yang diterima sistem berupa request dari pengirim pulsa (permintaan untuk registrasi, transfer pulsa, ganti password, hapus account) dalam bentuk pesan SMS dan dari administrator (perintah untuk Bind dan UnBind ke SMSC). Sedangkan keluaran sistem berupa konfirmasi dari pihak operator dalam format SMS mengenai status konfirmasi atas request yang diinginkan, baik untuk pengirim maupun penerima, dan tersimpan dalam logfile di server. Rancangan sistem dituangkan dalam bentuk context diagram dan data flow diagram di Gambar 4 dan Gambar 5.

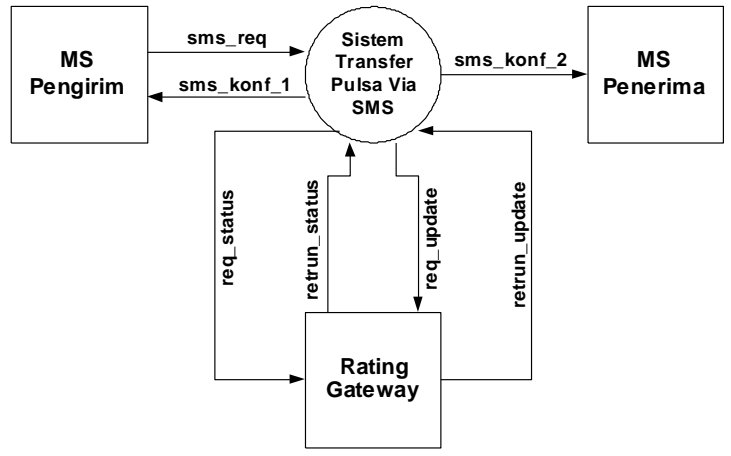

Gambar 4. Diagram Konteks

Ada beberapa tabel yang dibuat dan terlibat dalam sistem, sebagai berikut :
Tabel 1. Format Pesan

\begin{tabular}{|c|c|}
\hline \multicolumn{2}{|l|}{$\because:$ REG ISTRAS I } \\
\hline Format & reg + [login] + [password] \\
\hline Contoh & reg ahmad 150281 \\
\hline Konfirmasi Sukses & $\begin{array}{l}\text { Selamat Anda telah terdaftar di } \\
\text { Sistem Transfer Pulsa. Login = } \\
\text { "ahmad", Password = "150281". }\end{array}$ \\
\hline \multirow[t]{2}{*}{ Konfirmasi Error } & Maaf, nomor anda telah terdaftar \\
\hline & Maaf format pesan Anda salah \\
\hline \multicolumn{2}{|c|}{ :: TRANSFER PULSA } \\
\hline Format & $\begin{array}{l}\text { transfer + [login] + [password] + } \\
\text { [tujuan] + [jumlah pulsa] }\end{array}$ \\
\hline Contoh & $\begin{array}{l}\text { transfer ahmad } 150281 \\
6285621967932000\end{array}$ \\
\hline $\begin{array}{l}\text { Konfirmasi } \\
\text { Pengirim Sukses }\end{array}$ & $\begin{array}{l}\text { Anda telah berhasil mengirim pulsa } \\
\text { senilai Rp [jumlah pulsa] ke nomor } \\
\text { [penerima] }\end{array}$ \\
\hline $\begin{array}{l}\text { Konfirmasi } \\
\text { Penerima Sukses }\end{array}$ & $\begin{array}{l}\text { Selamat, Anda mendapat } \\
\text { tambahan pulsa senilai Rp [jumlah } \\
\text { pulsa] + dari [pengirim] }\end{array}$ \\
\hline \multirow[t]{7}{*}{ Konfirmasi Error } & Maaf, format pesan Anda salah \\
\hline & $\begin{array}{l}\text { Maaf, Anda tidak memasukkan } \\
\text { jumlah pulsa yang valid }\end{array}$ \\
\hline & $\begin{array}{l}\text { Maaf, transfer pulsa gagal } \\
\text { dilakukan }\end{array}$ \\
\hline & $\begin{array}{l}\text { Maaf, transfer pulsa gagal } \\
\text { dilakukan karena pulsa pada nomor } \\
\text { Anda tidak dapat diupdate }\end{array}$ \\
\hline & $\begin{array}{l}\text { Maaf, transfer pulsa gagal karena } \\
\text { pulsa pada nomor tujuan anda } \\
\text { tidak dapat dipudate }\end{array}$ \\
\hline & $\begin{array}{l}\text { Maaf, LOGIN dan PASSWORD Anda } \\
\text { tidak sama }\end{array}$ \\
\hline & $\begin{array}{l}\text { Maaf, nomor telephone Anda tidak } \\
\text { terdaftar }\end{array}$ \\
\hline \multicolumn{2}{|c|}{ :: GANTI PASSWORD } \\
\hline Format & $\begin{array}{l}\text { chg + [login] + [password_lama] + } \\
\text { [password_baru] }\end{array}$ \\
\hline Contoh & chg ahmad 150281090281 \\
\hline Konfirmasi Sukses & $\begin{array}{l}\text { Password baru anda adalah = } \\
\text { [password_baru] }\end{array}$ \\
\hline Konfirmasi Error & Maaf, format pesan Anda salah \\
\hline \multicolumn{2}{|c|}{$\because:$ HAPUS ACCOUNT } \\
\hline Format & del + [login] + [password] \\
\hline Contoh & del ahmad 090281 \\
\hline Konfirmasi Sukses & Account telah terhapus \\
\hline Konfirmasi Error & Maaf, format pesan Anda salah \\
\hline
\end{tabular}

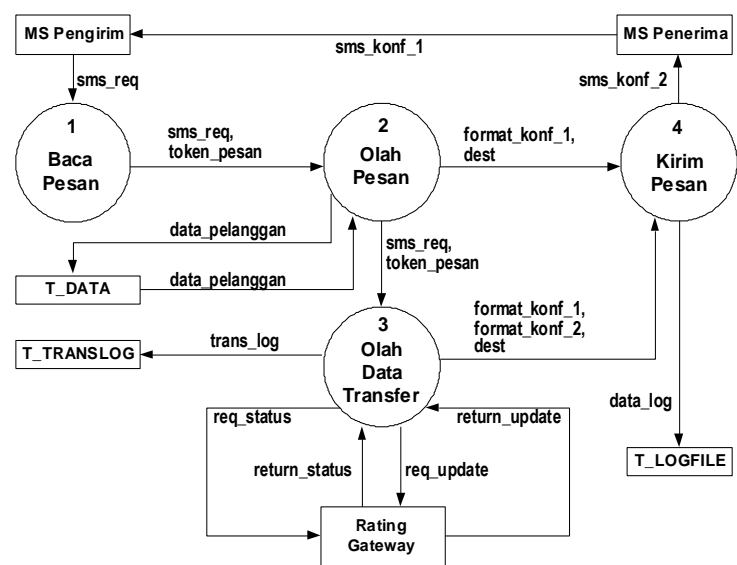

Gambar 5. Data Flow Diagram

- Struktur T_DATA

T_DATA adalah tabel berisi data pelanggan yang menggunakan layanan Sistem Transfer Pulsa, yang telah berhasil melakukan registrasi di sistem ini. Data disimpan di database lokal. 
- Struktur T_LOGFILE

T_LOGFILE adalah tabel berisi pencatatan aktifitas yang terjadi pada sistem secara umum, hasil konektivitas dengan pelanggan.

- Struktur T_TRANSLOG

T_TRANSLOG adalah tabel berisi pencatatan aktivitas transaksi transfer pulsa secara khusus.

Format pesan yang digunakan dalam sistem dirinci pada Tabel 1, mencakup kelompok-kelompok pesan untuk registrasi, transfer pulsa, ganti password, dan hapus account.

\section{Pengujian}

Setelah dilakukan transformasi rancangan basis data ke basis data fisik dan kode program ditulis untuk mengimplementasikan fungsionalitas sistem, maka dilakukan pengujian terhadap program. Pengujian dilakukan dengan menguji masing-masing fungsionalitas program, untuk meyakinkan bahwa semua fungsi berjalan dan terintegrasi dengan baik.

Selanjutnya dilakukan pengukuran langsung terhadap sistem untuk mengetahui kinerjanya. Pengukuran dilakukan dari sudut pandang kuantitatif dan kualitatif.

\subsection{Pengukuran kuantitatif}

Pengujian dilakukan dengan mengirimkan SMS request ke aplikasi Sistem Transfer Pulsa (alamat aplikasi di Short Number 5555), baik berupa registrasi, ganti password, hapus account, atau transfer pulsa. Pada pengujian ini difokuskan pada kebenaran output berdasarkan format pesan input yang telah ditetapkan.

Analisis kinerja sistem ini meliputi response time dan trafik yang dapat dilayani.

\section{- Response Time}

Response Time merupakan waktu pemrosesan yang dilakukan sistem terhadap request yang diberikan, mulai dari saat pengiriman request sampai diterimanya konfirmasi. Sistem ini dapat memenuhi QOS pengiriman SMS, yaitu dibawah 10 detik (untuk layanan transfer pulsa). Sistem ini dapat memproses pesan dari pengiriman pesan sampai konfirmasi dalam waktu sebagai berikut :
Kirim - konf pengirim : $\mathbf{8 . 7 5 9}$ detik
Kirim - konf penerima : $\mathbf{9 . 2 0 7}$ detik
Durasi proses di server : $\mathbf{3 . 1 9 3}$ detik

Sedangkan untuk layanan registrasi, ganti password, dan hapus account didapatkan rata-rata durasi proses di server sebagai berikut :

\begin{tabular}{|ll|}
\hline Registrasi & $\mathbf{0 . 0 5 3 4}$ detik \\
Ganti Password & $: \mathbf{0 . 0 3 5 7}$ detik \\
Hapus Account & $: \mathbf{0 . 0 3 7 7}$ detik \\
\hline
\end{tabular}

Pengujian juga dilakukan untuk mengetahui waktu akses basis data di server, dengan menggunakan jumlah data sebanyak 10, 500, 5000, dan 50000. Hasilnya diperlihatkan pada Tabel 2.

Tabel 2. Waktu Akses Basis Data di Server

\begin{tabular}{|c|c|}
\hline Jumlah Data & Rata-rata Durasi di Server \\
\hline 10 & 0.105 detik \\
\hline 500 & 0.117 detik \\
\hline 5000 & 0.366 detik \\
\hline 50000 & 3.504 detik \\
\hline
\end{tabular}

Terlihat bahwa jumlah data berpengaruh terhadap durasi proses di server. Semakin banyak data pelanggan yang mengikuti layanan transfer pulsa, durasi proses di server semakin lama. Hal ini dapat diatasi antara lain dengan penggunaan sistem basis data yang lebih baik, penempatan proses parsing di sisi SMSC.

\section{- Trafik}

Trafik pada penelitian ini dihitung dalam jumlah akses per jam. Yang dimaksud akses adalah sejak pesan dibaca sampai pengiriman konfirmasi. Berdasarkan hasil percobaan mengenai respons time, dapat dihitung jumlah transaksi yang dapat dilayani setiap detik adalah $1 / 8.759=\mathbf{0 , 1 1 4 2}$ akses/detik. Dalam satu jam berarti dapat dilayani sebanyak $0.114 \times 3600=\mathbf{4 1 1}$ akses/jam.

\subsection{Pengujian Kualitatif}

Pengujian kualitatif dilakukan menggunakan metoda kuesioner. Disebar sebanyak 30 kuesioner yang dibagikan secara acak. Pemilihan range umur $20-25$ tahun, disesuaikan dengan target pasar IM3 yang merupakan kaum muda. Sedangkan pemilihan lokasi di kampus STTTelkom mewakili kaum muda dengan intelektualitas dan frekuensi penggunaan telepon seluler yang relatif tinggi.

Dari kuesioner, didapatkan bahwa sistem transfer pulsa "sangat disetujui" oleh $\mathbf{6 0 \%}$ responden (18 orang), "disetujui" oleh $\mathbf{3 3 \%}$ responden (10 orang), dan $\mathbf{7 \%}$ responden (2 orang) menyatakan "ragu-ragu". Dari $\mathbf{9 7 \%}$ responden (28 orang) yang menyatakan dukungan, 24 orang (85.7\%) lebih memilih mekanisme transfer pulsa dilakukan melalui SMS, dan sisanya 4 orang (14.3\%) memilih melalui IVR atau USSD.

Mengenai kepuasan terhadap layanan yang telah dirancang, dari 24 orang yang mendukung layanan transfer pulsa via SMS, 10 orang (41.7 \%) menyatakan "puas", 13 orang (54.2 \%) menyatakan "cukup puas", dan 1 orang (1 \%) menyatakan "kurang puas". Sedangkan untuk kemudahan format pesan, 7 orang $(\mathbf{2 9 . 2} \%)$ menyatakan "sangat mudah", 17 orang $(\mathbf{7 0 . 8} \%)$ menyatakan "mudah", dan tidak ada yang mengatakan rumit. 
Dari hasil pengujian kualitatif, dapat dibuktikan bahwa Sistem Transfer Pulsa berbasis SMS ini, telah memenuhi harapan pengguna telepon seluler untuk mengatasi masalah keterbatasan pulsa dalam berkomunikasi. Persentase responden yang memiliki ekspektasi tinggi, penilaian terhadap sistem dan kemudahan format pesan, menunjukkan sistem ini layak dikatakan berhasil dan cukup menjanjikan untuk diimplementasikan.

\section{Kesimpulan dan Saran}

Sistem transfer pulsa merupakan suatu layanan baru yang dapat diberikan oleh operator untuk memanjakan pelanggannya, sehingga tetap dapat menjaga kelangsungan komunikasi ketika cadangan pulsa terbatas atau habis. Dari sisi respons time (waktu yang dibutuhkan untuk pemrosesan), sistem ini dapat memenuhi QoS pengiriman SMS, yaitu dibawah 10 detik. Sistem ini dapat memproses pesan sejak diterima di server sampai konfirmasi didapatkan dalam $\mathbf{8 . 7 5 9}$ detik untuk konfirmasi ke pengirim, dan $\mathbf{9 . 2 0 7}$ detik untuk konfirmasi ke penerima. Sementara durasi proses di server mencapai 3.193 detik per transfer pulsa. Sistem transfer pulsa ini dapat melayani trafik 411 SMS/jam. Secara umum, responden sangat berharap sistem ini dapat segera diimplementasikan. Dari pengujian sistem dan harapan pelanggan, mereka memiliki tingkat kepuasan dan harapan yang relatif tinggi.

Meski relatif murah, penggunaan media SMS dalam melakukan transfer pulsa masih mengharuskan pengirim pulsa untuk membayar ongkos pengiriman SMS request-nya. Perlu dicari alternatif media lain sehingga dapat mengurangi atau bahkan meniadakan sama sekali ongkos transfer pulsa. Sistem transfer pulsa antar operator juga menjadi isu yang cukup menarik untuk dikaji lebih jauh. Selain masalah teknis (interoperabilitas, keamanan dan integritas akses basis data, dan lainlain), juga terdapat masalah yang berkaitan dengan perbedaan tarif, prosedur dan birokrasi antaroperator telepon seluler.

\section{Daftar Pustaka}

[1] Derdack Software Engineering GmbH, 2002, SMSC Connectivity SDK 2.0.

[2] Firawati, D., 2003, Visualisasi Mekanisme Proses Billing Real Time pada Layanan Prabayar, Studi Kasus: Layanan Kartu Prabayar IM3 Smart PT. Indosat M3. STT Telkom.

[3] Indosat Multimedia Mobile, PT. 2003, User Guide Rating Gateway API.

[4] The International Engineering Consortium. Global System for Mobile Communication (GSM). http://www.iec.org
[5] The International Engineering Consortium. Wireless Short Message Service (SMS). http://www.iec.org

[6] The International Engineering Consortium. Prepaid Service. http://www.iec.org 